\title{
Greening Cardiology: Exploring the Sustainability Practices of Healthcare Workers in the Cardiac Catheterization Laboratory
}

\section{Azba Gurm ${ }^{1}$, Jessica Lehrich ${ }^{2 *}$ and Brahmajee K Nallamothu²}

${ }^{1}$ School of Literature, Science and Arts, University of Michigan, MI, USA

${ }^{2}$ Institute for Healthcare Policy and Innovation, University of Michigan, MI, USA

\begin{abstract}
Background: Hospitals produce a substantial amounts of waste. To understand the potential role of employees in reducing waste, we surveyed healthcare workers in the cardiac catheterization laboratory-a resource-intensive hospital area - about their personal practices regarding sustainability at work and at home.

Methods and results: We surveyed 52 full-time employees of the University of Michigan Cardiac Catheterization Laboratories using an anonymous online survey. Employees included all individuals working in a patient care capacity, such as physicians, nurses, technicians, medical assistants and administrators. Paired t-tests compared responses to parallel questions about recycling and energy saving habits between work and home. A total of 42 of $52(80.8 \%)$ respondents completed the survey with $12(28.6 \%)$ physicians and $30(71.4 \%)$ non-physicians. Recycling and energy saving habits were more evident on average at home than in the workplace across the majority of areas examined. Comparing sustainability habits between subpopulations, physicians were found to engage in energy saving habits at home significantly less often than non-physician employees (mean score, 2.3 versus $2.9 ; p=0.0014$ ) and employees under 40 years of age engaged in energy saving habits significantly less at work than employees over 40 years of age (mean score, 1.7 versus 2.1 ; $p=0.0322$ ).
\end{abstract}

Keywords: Sustainability; Cardiac catheterization laboratories; Recycling; Waste management

\section{Introduction}

At a time when diverse industries are prioritizing environmental responsibility, healthcare systems are still losing numerous opportunities to effectively reduce waste and conserve energy. Many of these lost opportunities are simple preventative measures which are often performed by employees in their daily lives [1-4]. Since the success of any sustainability initiative depends on the direct actions of people [5], we sought to understand the personal practices regarding sustainability of healthcare workers by contrasting their behavior at work with that at home. We focused on a diverse set of employees in the cardiac catheterization laboratory, a resource-intensive hospital area that involves multidisciplinary teams, and which sees inpatients and outpatients having both chronic and acute conditions.

\section{Methods}

Adopted from the Graham Sustainability Institute, an anonymous online survey pertaining to sustainability practices at home and work was distributed to 52 full-time employees at the University of Michigan Cardiac Catheterization Laboratories [6]. Employees included all individuals working in a patient care capacity. Because this study is focused on sustainability practices in clinical units, purely administrative personnel were excluded from participation. All questions used a consistent ordinal scale, ranging from "Always" (coded as a 4) to "Never/Not Applicable" (coded as a 1). The full survey is available in the supplementary appendix. Parallel questions about recycling and energy saving habits between work and home were compared via paired $t$ tests. The Wilcoxon Mann Whitney test was used to compare demographic trends in sustainability habits between respondents based on position (physicians and non-physician employees), gender (women and men), and age (employees less than 40 years old and more than 40 years old). These comparisons were assessed separately for home and work. Results were considered signification at $\mathrm{P} \leq 0.05$. All analyses were conducted with SAS version 9.3 (Cary,
NC). This study was approved by the institutional review board of the University of Michigan.

\section{Results}

A total of 42 of $52(80.8 \%)$ respondents completed the survey. Descriptive statistics for this population are displayed in Table 1. On average, recycling and energy saving habits were more evident at home than in the workplace (Figure 1). A similar pattern was seen for each individual survey question, with participant sustainability habits at home scoring consistently higher, indicating a greater degree of sustainability engagement at home than at work for the same area of focus (Figure 1). In fact, all sustainability habits were found to be significantly more prevalent at home with the exception of using motion sensor power strips and recycling bottles, containers, and paper products. Comparing sustainability habits between subpopulations, physicians were found to engage in energy saving habits at home significantly less often than non-physician employees (mean score, 2.3 versus 2.9; $\mathrm{p}=0.0014$ ) and employees under 40 years of age engaged in energy saving habits significantly less at work than employees over 40 years of age (mean score, 1.7 versus $2.1 ; \mathrm{p}=0.0322$ ). All other comparisons were non-significant at both locations.

\section{Discussion}

Our key finding is that employees in the cardiac catheterization laboratory engaged in sustainability practices at home significantly

*Corresponding author: Jessica Lehrich, MS, Institute for Healthcare Policy and Innovation, University of Michigan, Michigan, MI, United States of America, E-mail: jlehric@med.umich.edu

Received July 05, 2016; Accepted July 16, 2016; Published July 20, 2016

Citation: GurmA, Lehrich J, Nallamothu BK (2016) Greening Cardiology: Exploring the Sustainability Practices of Healthcare Workers in the Cardiac Catheterization Laboratory. Adv Recycling Waste Manag 1: 103.DOI: 10.4172/2475-7675.1000103

Copyright: (c) 2016 Gurm A, et al. This is an open-access article distributed under the terms of the Creative Commons Attribution License, which permits unrestricted use, distribution, and reproduction in any medium, provided the original author and source are credited. 

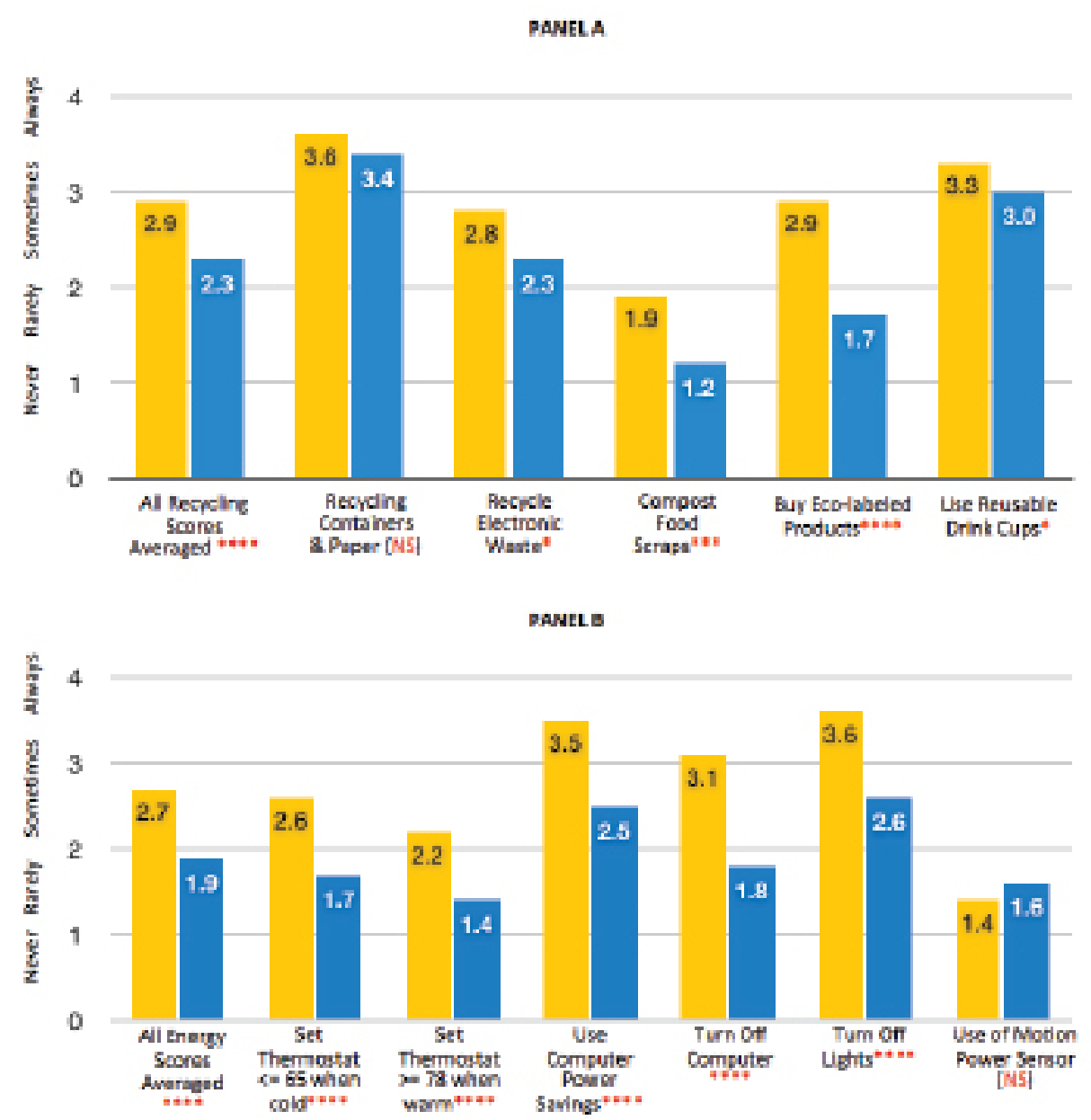

$\begin{array}{ll} & \text { Mean Home } \\ \text { NS } & \text { Mean Work } \\ * & \text { Not Significant } \\ * * & \text { P-value, 0.01-0.05 } \\ \text { *** } & \text { P-value, } \quad \text { 0.001-0.01 } \\ \text { **** } & \text { P-value, 0.0001-0.001 } \\ & \text { P-value, }<0.0001\end{array}$

Figure 1: Mean scores of survey responses for Recycling (Panel A) and Energy questions (Panel B).

more consistently than in the workplace. This finding suggests that healthcare employees have the personal mindset to be sustainable, but opportunities provided in the work environment are not being potentially exploited to what can be achieved at home. Healthcare systems may improve sustainability by better designing care processes to leverage opportunities for recycling expansion and waste-reduction in addition to pushing employee education toward these behaviors.

The habits that vary most significantly between home and work were turning off lights when leaving a room, buying products with eco-labels, composting, and turning off computers after use. A possible reason for this is that these habits are likely perceived as less of a personal obligation at work as compared to home. Additionally, the personal costs associated with these activities may incentivize individual behavior toward greater conservation; this incentive is less likely in the workplace. The only exception to this trend of better habits at home was the use of motion sensor power strips, which were used more at work. This lower occurrence may be due to the high cost of motion sensors in people's homes.

By contrast, the only habit that had no significant difference between home and work-recycling bottles, containers, and paper products-may be due to the fact that this particular initiative is at the forefront of worldwide sustainability campaigns and widely available. Since the opportunity to recycle these products is present throughout the workplace, there may be little difference between employee behaviors at work and at home. Although it's just one example, this is a promising indication that employee sustainability habits reflect the availability and awareness of sustainability opportunities within a given environment [5].

The only significant differences we identified across different 


\begin{tabular}{|c|c|c|}
\hline Demographic Category & Occupation & N (\%) \\
\hline \multirow{2}{*}{ Physician } & Attending Physician & $6(14.3)$ \\
\hline & Resident/Fellow & $6(14.3)$ \\
\hline \multirow{5}{*}{ Non-Physician } & Nurse & $6(14.3)$ \\
\hline & Adv. Practitioner & $5(11.9)$ \\
\hline & Cardiac Cath Lab Tech & $14(33.3)$ \\
\hline & Medical Assistant & $2(4.8)$ \\
\hline & Administrator/Manager & $3(7.1)$ \\
\hline Demographic Category & Age Group & $\mathrm{N}(\%)$ \\
\hline \multirow{3}{*}{$<40$} & $\leq 21$ & 0 \\
\hline & $22-29$ & $4(9.5)$ \\
\hline & $30-39$ & $19(45.2)$ \\
\hline \multirow{3}{*}{$>40$} & $40-49$ & $13(31.0)$ \\
\hline & $50-59$ & $5(11.9)$ \\
\hline & $60-69$ & $1(2.4)$ \\
\hline Demographic Category & Sex & $\mathrm{N}(\%)$ \\
\hline Male & Male & $21(50)$ \\
\hline Female & Female & $20(47.6)$ \\
\hline Dropped & No Response & $1(2.4)$ \\
\hline
\end{tabular}

Table 1: Demographic composition of survey participants.

groups of respondents was that physicians may engage less in energyconservation behaviors at home than non-physicians and that employees under 40 engaged less in energy-conservation behaviors at work than employees over 40 . This general lack of difference across respondents suggests that no single group need be specifically targeted in sustainability initiatives.

This study has important limitations. We examined a small number of employees in only a single area of our facility. These results may not be representative of other areas of our hospital or other facilities, and it is possible that sustainability practices vary substantially across different locations even within the same facility. Future research will need to build on these results in order to better examine sustainability practices within centers, between centers, and across varying demographic groups. Finally, we did not correlate these responses with actual measurement of waste and energy reduction with sustainability practices or determine their impact on hospital expenses.

\section{Conclusions}

Healthcare employees appear to have the personal mindset to be sustainable, but the hospital potentially offers fewer opportunities to do so than their own homes, reducing their recycling and energy saving habits at work.

\section{Disclosures}

Dr. Nallamothu reports being on the cardiac scientific advisory board for United Healthcare.

\section{References}

1. Wormer BA, Augenstein VA, Carpenter CL, Burton PV, Yokeley WT, et al (2013) The Green Operating Room: Simple Changes to Reduce Cost and Our Carbon Footprint. The American Surgeon 79: 666-671.

2. Riedel LM (2011) Environmental and financial impact of a hospital recycling program. AANA J 79: S8-14.

3. World Health Organization, Health Care without Harm (2009) Healthy Hospitals Healthy Planet, Healthy People: Addressing Climate Change in Health Care Settings. World Health Organization, p: 28.

4. Rygielski L, Benz P (2011) Going Green While Improving Quality of Care Sustainable Facility 36: 16.

5. Johns Hopkins Medicine (2013) Officials Report Early Success in Campaign to Reduce Trash and Medical Waste at The Johns Hopkins Hospital, USA.

6. Callewaert J, Marans R (2013) "Sustainability Cultural Indicators." Survey. Graham Sustainability Institute, University of Michigan, USA. 